\title{
The Clinical Significance of Circulating Microparticles Concerning Thrombosis in BCR/ABL1-negative Myeloproliferative Neoplasms
}

\author{
MOHAMED HUSSAM ASWAD ${ }^{1,2}$, JARMILA KISSOVA ${ }^{1,2}$, PETRA OVESNA ${ }^{3}$, \\ LUCIE RIHOVA $^{1,2}$ and MIROSLAV PENKA ${ }^{1,2}$ \\ ${ }^{1}$ Department of Clinical Hematology, University Hospital Brno, Brno, Czech Republic; \\ ${ }^{2}$ Faculty of Medicine, Masaryk University, Brno, Czech Republic; \\ ${ }^{3}$ Institute of Biostatistics and Analyses, Faculty of Medicine, Masaryk University, Brno, Czech Republic
}

\begin{abstract}
Background/Aim: This work aimed to prospectively evaluate the clinical significance of circulating microparticles (MPs) in relation to thrombotic risk factors and thrombotic complications in patients with $B C R / A B L 1$-negative myeloproliferative neoplasms (MPN). Patients and Methods: In a cohort of 206 patients with $M P N$, MPs' procoagulant activity was measured by the Zymuphen functional assay in 429 samples, while plateletand erythrocyte-MPs were enumerated by flow cytometry in 558 samples. Results: MPN patients had higher MP levels than the control group. The levels of MPs were higher in male patients, smokers, and those who were older than 60 years, and in the presence of JAK2 $2^{V 617 F}$ mutation, history of thrombosis, platelets $>400 \times 10^{9} / \mathrm{l}$, hematocrit $>45 \%$, or leukocytes $>10 \times 10^{9} / l$. Cytoreductive treatment reduced MP levels, with anagrelide being associated with lower MP levels than hydroxyurea. Conclusion: The relationship with thrombotic risk factors indicates a possible role of MPs in the complex thrombotic mechanism, though cytoreductive treatment seems to affect this role through reducing MP levels.
\end{abstract}

Circulating microparticles (MPs) are cell-derived vesicles ranging in size between 0.1 and $1 \mu \mathrm{m}$; are non-nucleated, have no synthetic capability, and contain a membrane

This article is freely accessible online.

Correspondence to: Mohamed Hussam Aswad, MD, Department of Clinical Hematology, University Hospital Brno, Jihlavska 20, Brno 625 00, Czech Republic. Tel: +42 0608597958, e-mail: aswad.mohamedhussam@fnbrno.cz

Key Words: Myeloproliferative neoplasm, microparticle, procoagulant activity, thrombosis, anagrelide, hydroxyurea. skeleton with antigens indicating their cellular origin (1). Most commonly, MPs originate from platelets and megakaryocytes but also erythrocytes, leukocytes, endothelial cells, and tumor cells during activation or apoptosis $(1,2)$. MPs enhance coagulation by exposing the procoagulant anionic phosphatidylserine (PS) on their surface and/or expressing functional tissue factor (TF) (3). A higher level of MPs was detected in many pathological conditions, including autoimmune, hematological, cardiovascular, infectious, nephrological, and oncological disorders (1). BCR-ABL1 negative myeloproliferative neoplasms (MPN) belong to oncological disorders that have been linked to elevated levels of MPs (4-8).

MPN are clonal myeloid disorders, including polycythemia vera (PV), essential thrombocythemia (ET), and primary myelofibrosis (PMF). Patients with MPN show excessive proliferation of hematopoietic precursors in the bone marrow leading to abundant levels of mature blood cells being released into the circulation (9). Thrombosis is a common complication of MPN that significantly impacts patients' mortality, accounting for the death of $33 \%$ of PV, $16 \%$ of ET, and $2 \%$ of PMF patients (10-12). Thrombosis may occur at venous, arterial, or microcirculatory sites and can be the first sign of MPN. Management of MPN is based on predicting the risk of thrombosis and starting treatment to prevent complications in vulnerable patients (13). Thus, identifying prognostic factors is the initial step in MPN patients. Thrombosis in MPN has been linked to higher MPs levels, and utilization of MPs as a surrogate biomarker of thrombosis has been suggested $(6,8,14)$.

\section{Patients and Methods}

Patients. Analyses of MPs were conducted in a cohort of 206 patients diagnosed with BCR/ABL1-negative MPN according to the WHO diagnostic criteria with a median age at diagnosis of 57 (range $=28-78$ ) years. Patients have been under follow-up since 2003 to the present time at the Department of Clinical Hematology of the 
Table I. Characteristics of patients with BCR-ABL1 negative myeloproliferative neoplasms.

\begin{tabular}{lcc}
\hline & $\mathrm{N}$ & $\%(\mathrm{n}=206)$ \\
\hline Age & & \\
Age >60 years & 87 & 42.2 \\
Gender & & \\
Male & 91 & 44.2 \\
Female & 115 & 55.8 \\
MPN subtype & & \\
ET & 119 & 57.8 \\
PV & 51 & 24.8 \\
PMF & 36 & 17.4 \\
Driver mutations & & \\
JAK2V617F & 155 & 75.2 \\
CALR & 37 & 18 \\
MPL & 4 & 1.9 \\
Triple-negative & 10 & 4.9 \\
Cardiovascular risk factors & & \\
Hypertension & 121 & 58.7 \\
Obesity/BMI>30 & 28 & 13.6 \\
Hyperlipidemia & 51 & 24.8 \\
Diabetes mellitus & 29 & 14.1 \\
Tobacco use & 57 & 27.7 \\
Thrombosis & & \\
Arterial events & 41 & 19.9 \\
Venous events & 36 & 17.5 \\
Microvascular disturbance & 9 & 4.4 \\
Treatment & & \\
Cytoreductive therapy & 156 & 75.7 \\
\hline \\
\hline PP: Myeloprolfative
\end{tabular}

MPN: Myeloproliferative neoplasms; ET: essential thrombocythemia; PV: polycythemia vera; PMF: primary myelofibrosis.

University Hospital Brno, Czech Republic. Blood sampling for examining MPs and a full blood count (FBC) was performed concurrently for patients between the years 2016 and 2018 within regular time intervals during their routine check-ups. The local committee approved the analysis, and all patients signed informed consent.

Thrombotic complications were recorded for all patients according to the thrombosis site as arterial events (ATE), venous (VTE), and microvascular disturbance (MVD). Thrombotic events were classified according to the time of event as occurring after diagnosis (during the follow-up) or within one month before diagnosis (at diagnosis). Any event that occurred before this period was considered as a history of thrombosis (before diagnosis). At the end of the study, 156 patients were on cytoreductive therapy: 73 patients were on anagrelide (ANA); 37 on hydroxyurea (HU); 10 on interferon-alpha; 3 on ruxolitinib; and 33 on a combination of two of the above agents. The characteristics of the patients are summarized in Table I.

Pre-analytical conditions for examination of MPs. After using a light tourniquet for a short period $(<1 \mathrm{~min})$, blood samples were collected into the vacutainer system. Sodium citrate was used for the examination of MPs, and EDTA was used for molecular studies and FBC evaluation. To avoid inadvertent production of MPs: (i) 21-gauge needles were used for venipuncture; (ii) the first three milliliters of blood were discarded; (iii) plasma was processed within approximately $120 \mathrm{~min}$; (iv) platelets with other large blood components were excluded through a centrifugation process.

For quantification of MPs using flow cytometry (FCM), plateletpoor-plasma (PPP) was preferred to avoid losing MPs. PPP was prepared using a one-phase centrifugation process at $2,500 \times \mathrm{g}$ for 15 min at room temperature (RT) to avoid breaks, which can affect the credibility of the results. Then $200 \mathrm{ml}$ of the plasma supernatant was carefully moved into a polypropylene hemolysis tube with a micropipette to avoid mixing the plasma with the cellular layer. The plasma supernatant was then immediately processed for the FCM examination.

To measure the procoagulant activity of MPs, platelet-free plasma (PFP) was used so that samples could be stored frozen for later analysis. PFP was reproduced using a centrifugation process at $1,500 \times g$ for $15 \mathrm{~min}$ at RT; then, the PPP supernatant was further centrifuged for another 2 min at $13,000 \times g$ at RT and was then snapfrozen at $-80^{\circ} \mathrm{C}$. On the day of analysis, an aliquot of plasma was thawed for $15 \mathrm{~min}$ at $37^{\circ} \mathrm{C}$ before use. Thawed specimens were stored at RT and tested within four hours.

Analytical conditions for the examination of MPs. The FCM assay was performed by using FC500 Cytomics (Beckman Coulter, Hialeah, FL, USA). After incubation of PPP with CD41-PC7 (Beckman Coulter), CD235a-PE, and annexin V-FITC (both from EXBIO, Prague, Czech Republic) in $\mathrm{Ca}^{++}$buffer, calibrated beads FlowCount (Beckman Coulter) were added to enumerate the detected MPs. The sample was immediately analyzed by a protocol that uses Megamix beads (Biocytex, Marseille, France) for MPs size gating. Platelet-derived MPs (PMPs) were identified as doublepositive annexin-V and CD41 (Beckman Coulter) events, while erythrocyte-derived MPs (RMPs) were identified as double-positive annexin- $\mathrm{V}$ and $\mathrm{CD} 235 \mathrm{a}$ (EXBIO) events. The total number of samples analyzed by FCM were 558, and the mean number of samples obtained from patients was 2.7 samples per patient.

Measurement of the procoagulant activity levels of MPs (MPactivity) in PFP by using a functional assay called Zymuphen MPactivity (Hyphen Biomed, Neuville-sur-Oise, France). In this assay, the diluted plasma samples are incubated with Factor Xa and thrombin inhibitors in an ELISA plate coated with biotinylated annexin V and streptavidin. After a washing step, Factor Xa and Va are added together with prothrombin. Depending on the presence of MPs, the FXa-FVa complex converts prothrombin to thrombin which is directly proportional to the concentration of phospholipids on the surface of MPs. The generated amount of thrombin is measured, and results are expressed as nanomolar phosphatidylserine equivalent (nmol/l). The total number of samples analyzed using the Zymuphen assay were 429 , and the mean number of samples obtained from patients was 2.1 samples per patient.

Statistical analyses. Categorical variables are summarized as absolute and relative frequencies, while continuous variables are presented as median and interquartile range (IQR). Levels of PMPs, RMPs, and MPs procoagulant activity were compared between MPN patients and the control group, which consisted of 20 healthy individuals. Linear mixed-effects models were applied to evaluate the impact of different factors on the levels of MPs. Models included the patient's identification number as a random effect since one patient had more than one examination of MPs. Original values of MPs were log-transformed due to their log-normal distribution 

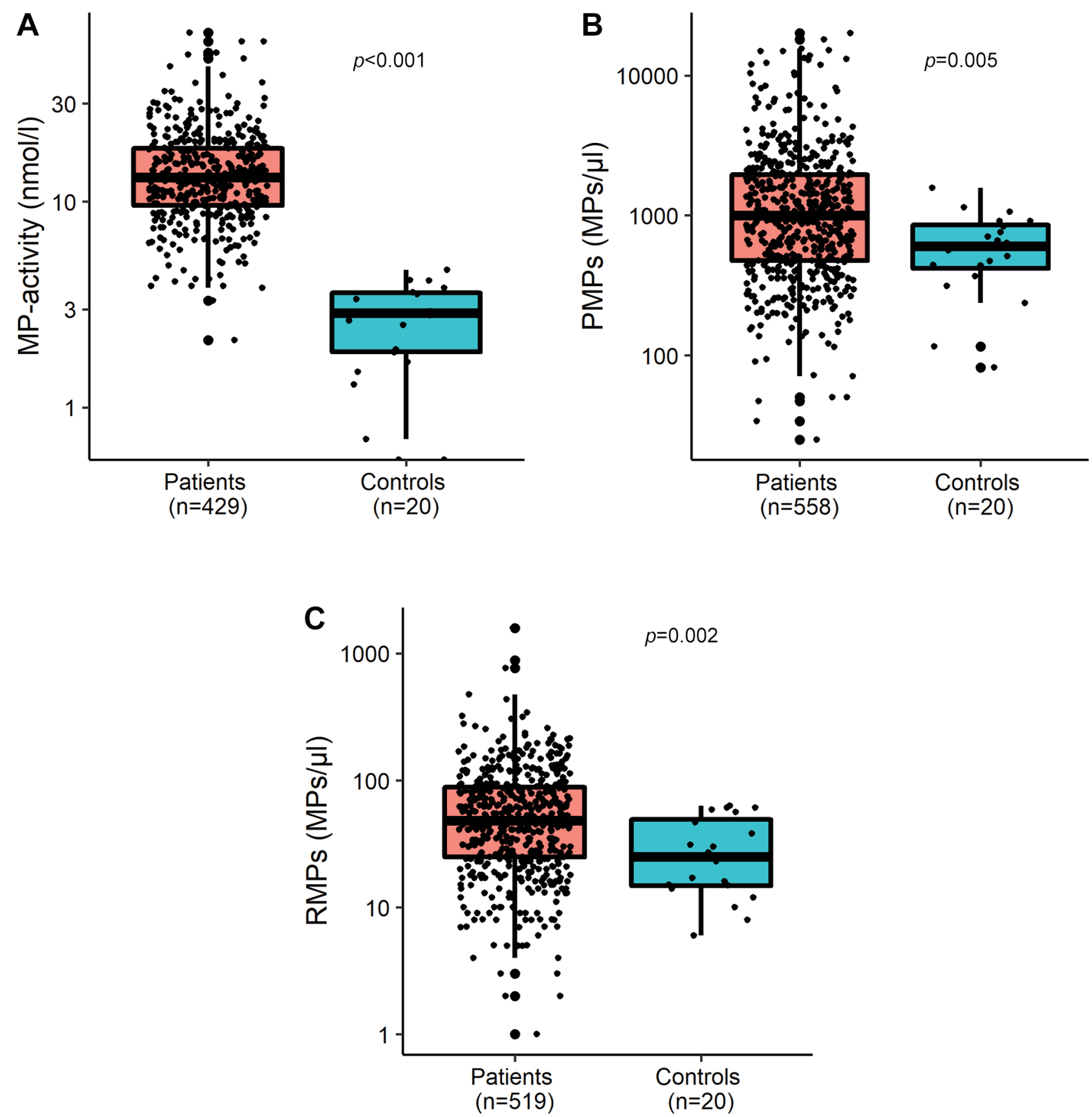

Figure 1. Comparison between MPN patients and control group for the procoagulant activity of microparticles (A), count of platelet microparticles (B), and count of erythrocyte microparticles $(C)$.

for the purpose of the model. Univariate models were followed by multivariate ones, including sex, MPN type, age at MPs examination, JAK2 $2617 \mathrm{~F}$ status, tobacco smoking, thrombosis occurrence before MPN diagnosis, and FBC values at the time of MPs examination. All tests were performed as two-sided at the significance level of alpha $=0.05$. Analyses were performed in IBM SPSS Statistics and R software.

\section{Results}

The normal levels of MP-activity are usually less than 5 nmol/1. This was confirmed by the healthy group results, where all values of the activity of MPs were lower than 5 (range=0-4.415) nmol/1. MPN patients were found to have 
in vivo $35: 3345-3353(2021)$

Table II. Evaluation of values of PMPs, RMPs, and MP-activity in MPN patients according to the presence of thrombotic risk factors and in relation to blood count.

\begin{tabular}{|c|c|c|c|}
\hline & PMPs $(\mathrm{MPs} / \mu \mathrm{l})^{1}$ & RMPs $(\mathrm{MPs} / \mu \mathrm{l})^{1}$ & MP-activity $(\mathrm{nmol} / \mathrm{l})^{1}$ \\
\hline \multicolumn{4}{|l|}{ Gender } \\
\hline Male (n=91) & $1,031(509-1,999)$ & $48(26-86)$ & $14.3(10.9-19.9)^{* * *}$ \\
\hline Female $(\mathrm{n}=115)$ & $993(450-1,931)$ & $48.5(23.5-90)$ & $11.6(9-16.1)$ \\
\hline \multicolumn{4}{|c|}{ Age at MPN diagnosis (years) } \\
\hline$>60(n=87)$ & $1012.5(504-2,005)$ & $49(26-94)$ & $13.8(10.6-19.5)^{* *}$ \\
\hline$\leq 60(n=119)$ & $990.5(469-1,922)$ & $48(24-87)$ & $12.4(8.9-16.5)$ \\
\hline \multicolumn{4}{|l|}{ Tobacco smoking } \\
\hline Yes $(\mathrm{n}=57)$ & $964(499-2,186)$ & $48(23-85)$ & $13.7(11.2-20.6)^{* *}$ \\
\hline No $(n=149)$ & $1026.5(463-1,917)$ & $49(25-90)$ & $13.1(9.6-17)$ \\
\hline \multicolumn{4}{|c|}{ History of thrombosis before MPN diagnosis } \\
\hline Yes $(n=37)$ & $1087(627-2,186)$ & $46.5(26-114)$ & $14.1(10.9-19.5)^{*}$ \\
\hline No $(n=169)$ & $990.5(457-1,918.5)$ & $48(25-87)$ & $12.8(9.4-17.7)$ \\
\hline \multicolumn{4}{|c|}{ JAK2V617F mutation } \\
\hline Positive $(\mathrm{n}=155)$ & $1063.5(510-1,997.5)^{*}$ & $49(25-92.5)$ & $13.2(9.8-18.7)$ \\
\hline Negative $(\mathrm{n}=51)$ & $779(412-1,585)$ & $46(23-86)$ & $12.9(8.9-16.3)$ \\
\hline \multicolumn{4}{|c|}{ Platelets at MPs examination $\left(\times 10^{9} / 1\right)$} \\
\hline$>400(\mathrm{n}=101)$ & $1,163(616-2,249) * * *$ & $51(23-87)$ & $13.4(10.3-18.6)$ \\
\hline$\leq 400(\mathrm{n}=105)$ & $825.5(378-1,590)$ & $48(26-91)$ & $12.8(8.9-17.6)$ \\
\hline \multicolumn{4}{|c|}{ Hematocrit at MPs examination } \\
\hline$>45 \%(\mathrm{n}=41)$ & $1,297(699-2,395)^{* *}$ & $59.5(29-110.5)$ & $16.9(11.2-22.8) * * *$ \\
\hline$\leq 45 \%(\mathrm{n}=65)$ & $945(428-1,825)$ & $47(24-86)$ & $12.5(9.2-16.5)$ \\
\hline \multicolumn{4}{|c|}{ Leukocytes at MPs examination $\left(\times 10^{9} / 1\right)$} \\
\hline$>10(\mathrm{n}=76)$ & $969(411-1,906)$ & $55(31-98) *$ & $13.8(10.66-19.9)^{*}$ \\
\hline$\leq 10(\mathrm{n}=130)$ & $1007.5(499-1,956)$ & $46(23-85)$ & $12.8(9.24-16.49)$ \\
\hline
\end{tabular}

${ }^{1}$ Values denote median and interquartile range. MPs: Microparticles; PMPs: platelet microparticles; RMPs: erythrocyte microparticles; MP-activity: procoagulant activity of microparticles. ${ }^{*} p<0.05, * * p<0.01, * * * p<0.001$.

higher levels of MPs than the control group. As shown in Figure 1, MPN patients had significantly higher levels of PMPs, RMPs, and MP-activity than healthy individuals, $(p=0.005, p=0.002, p<0.001$, respectively).

Table II shows the values of MPs in relation to thrombotic risk factors in MPN. MP-activity levels were related to sex and age: its abnormal values were significantly increased in males $(p<0.001)$ and in patients who were $>60$ years old at the time of MPN diagnosis $(p=0.003)$. A similar relationship was found in patients with a history of thrombotic events before MPN diagnosis compared to those without such events $(p=0.017)$. Tobacco smoking was the only cardiovascular risk factor associated with higher levels of MP-activity $(p=0.001)$. Other cardiovascular risk factors, including hypertension, hyperlipidemia, diabetes mellitus, and obesity, did not affect the results of the examination of MPs (data not shown). The presence of JAK2 $2^{\mathrm{V} 617 \mathrm{~F}}$ mutation was associated with increased PMPs count $(p=0.022)$. Although the difference in MP-activity and RMPs levels did not show significant differences, average values were higher in $\mathrm{JAK} 22^{\mathrm{V} 617 \mathrm{~F}}$-mutated patients (Table II). We found a relation between the levels of MPs and the results of concurrently performed FBCs, shown in Table II. Patients presented with platelet count $>400 \times 10^{9} / 1$ had significantly increased PMPs count $(p<0.001)$. Hematocrit $>45 \%$ was associated with significantly increased levels of PMPs and MP-activity, respectively $(p=0.002, p<0.001)$. Similarly, levels of RMPs and MP-activity were elevated in patients with leukocytosis $>10 \times 10^{9} / 1$, respectively $(p=0.015$, $p=0.021$ ).

In multivariate analyses, only male sex and tobacco smoking were the thrombotic risk factors associated with increased levels of MP-activity, $(p=0.001, \quad p=0.033$, respectively). Also, these models showed a statistically significant relation between PMPs count and platelet count $(p<0.001)$ and hematocrit value $(p=0.007)$. In addition, levels of MP-activity were significantly related to hematocrit value $(p<0.001)$.

Regarding thrombotic complications, patients who had thrombosis anytime had higher pathological levels of MPactivity than thrombosis-free patients (median: 13.5 vs. 12.8 $\mathrm{nmol} / 1, p=0.012)$. However, when analyzing MPs results in the 29 patients who had thrombotic complications during the follow-up, no significant differences were found.

MPs levels were further analyzed in the context of cytoreductive treatment at the time of blood sampling (Table III). Samples obtained when using cytoreduction showed a significantly lower PMPs count than those obtained when no 
Table III. Levels of MPs and procoagulant activity in relation to cytoreductive treatment in MPN patients.

\begin{tabular}{|c|c|c|c|}
\hline & PMPs $(\mathrm{MPs} / \mu \mathrm{l})^{1}$ & RMPs $(\mathrm{MPs} / \mu \mathrm{l})^{1}$ & MP-activity $(\mathrm{nmol} / \mathrm{l})^{1}$ \\
\hline \multicolumn{4}{|c|}{ Cytoreductive therapy when blood sampling } \\
\hline Yes $(n-s=421)$ & $963(438-1,906)^{*}$ & $51(25-88)$ & $12.8(9.43-18.1)$ \\
\hline No $(n-s=137)$ & $1,174(571-2,254)$ & $45(24-101)$ & $13.8(9.9-18.92)$ \\
\hline \multicolumn{4}{|c|}{ Anagrelide-monotherapy when blood sampling } \\
\hline Yes $(n-s=206)$ & $804(354-1,725)^{*}$ & $45(23-82)$ & $11.93(8.9-15.87)^{*}$ \\
\hline No $(n-s=267)$ & $1,017(494-2,121)$ & $49(25-101)$ & $13.8(9.94-19.5)$ \\
\hline \multicolumn{4}{|c|}{ Hydroxyurea-monotherapy when blood sampling } \\
\hline Yes $(n-s=94)$ & $1015(477-2,264)$ & $58(23-118)$ & $14.11(10.3-20.5)$ \\
\hline No $(n-s=378)$ & $943(415-1,811)$ & $46(24-84)$ & $12.9(9.5-17.7)$ \\
\hline
\end{tabular}

${ }^{1}$ Values denote median and interquartile range. PMPs: Platelet microparticles; RMPs: erythrocyte microparticles; MP-activity: procoagulant activity of microparticles; n-s: number of samples. $* p<0.05$.

Table IV. Clinical and laboratory characteristics of patients receiving anagrelide or hydroxyurea as a cytoreductive monotherapy.

\begin{tabular}{|c|c|c|c|}
\hline & $\begin{array}{l}\text { Anagrelide } \\
\operatorname{arm}(n=73)\end{array}$ & $\begin{array}{c}\text { Hydroxyurea } \\
\text { arm }(n=37)\end{array}$ & $p$-Value \\
\hline \multicolumn{4}{|l|}{ Age at MPN diagnosis } \\
\hline Median (IQR) & $51(42.5-63)$ & $73(66-78)$ & $<0.001$ \\
\hline$>60$ years, $\mathrm{n}(\%)$ & $19(26)$ & $29(78.4)$ & $<0.001$ \\
\hline \multicolumn{4}{|l|}{ Gender } \\
\hline Female, n (\%) & $40(54.1)$ & $18(48.6)$ & 0.542 \\
\hline \multicolumn{4}{|l|}{ Mutation } \\
\hline $\mathrm{JAK}^{2 \mathrm{~V} 617 \mathrm{~F}}, \mathrm{n}(\%)$ & $48(65.8)$ & 35 (94.6) & 0.001 \\
\hline \multicolumn{4}{|l|}{ MPN subtype } \\
\hline PV, n (\%) & $8(11)$ & $16(43.2)$ & $<0.001$ \\
\hline $\mathrm{ET}, \mathrm{n}(\%)$ & $52(71.2)$ & $15(40.5)$ & \\
\hline PMF, n (\%) & $13(17.8)$ & $6(16.2)$ & \\
\hline \multicolumn{4}{|l|}{ Thrombosis } \\
\hline Anytime, n (\%) & $23(31.5)$ & $21(56.8)$ & 0.011 \\
\hline $\begin{array}{l}\text { Before MPN } \\
\text { diagnosis, } \mathrm{n}(\%)\end{array}$ & $10(13.7)$ & $14(37.8)$ & 0.004 \\
\hline $\begin{array}{l}\text { At MPN diagnosis, } \\
\text { n }(\%)\end{array}$ & $6(8.2)$ & $5(13.5)$ & 0.382 \\
\hline $\begin{array}{l}\text { During follow-up, } \\
\mathrm{n}(\%)\end{array}$ & $11(15.1)$ & 7 (18.9) & 0.606 \\
\hline \multicolumn{4}{|l|}{$\begin{array}{l}\text { Cardiovascular risk } \\
\text { factors }\end{array}$} \\
\hline At least one, n (\%) & $57(78.1)$ & $35(94.6)$ & 0.036 \\
\hline \multicolumn{4}{|l|}{ IPSET-thrombosis score } \\
\hline Low, n (\%) & $18 / 51(35.3)$ & $0 / 15(0)$ & 0.008 \\
\hline Intermediate, $\mathrm{n}(\%)$ & $4 / 51(7.8)$ & $0 / 15(0)$ & \\
\hline High, n (\%) & $29 / 51(56.9)$ & $15 / 15(100)$ & \\
\hline \multicolumn{4}{|l|}{ MPs values 1} \\
\hline PMPs (MPs/ $/ \mu \mathrm{l})$ & $828(359-1761)$ & $963.5(450-2233)$ & 0.014 \\
\hline RMPs (MPs/ $/ \mu \mathrm{l})$ & $45(23-79)$ & $52.5(22.5-115)$ & 0.167 \\
\hline MP-activity (nmol/l) & $12.45(8.9-16.46)$ & $15.14(10.58-20.88)$ & 0.01 \\
\hline
\end{tabular}

${ }^{1}$ Values denote median and interquartile range, in anagrelide arm: $\mathrm{n}=73$ and in hydroxyurea arm: $n=37$. IQR: Interquartile range; MPN: myeloproliferative neoplasms; PV: polycythemia vera; ET: essential thrombocythemia; PMF: primary myelofibrosis; IPSET-thrombosis: International Prognostic Score for thrombosis for ET; MPs: microparticles; PMPs: platelet microparticles; RMPs: erythrocyte microparticles; MPactivity: procoagulant activity of microparticles. Significant $p$-Values are shown in bold. cytoreduction was used $(p=0.018)$. The effect of the most commonly used cytoreductive monotherapies (ANA, HU) on the levels of MPs was studied (Table III). When only ANA was received at blood sampling, significantly lower PMPs and MP-activity levels were detected (both $p=0.011$ ). By contrast, when only HU was used, no significant differences were found in MPs levels. The clinical and laboratory characteristics of patients with HU or ANA monotherapy are shown in Table IV. Patients in the HU arm were significantly older and presented more frequently with thrombotic events before diagnosis and $\mathrm{JAK} 2^{\mathrm{V} 617 \mathrm{~F}}$ mutation than patients in the anagrelide arm. PMPs and MP-activity levels were significantly lower in the anagrelide arm, respectively $(p=0.014, p=0.01)$.

\section{Discussion}

The prothrombotic state of MPN patients is a multifactorial matter. It stems also from the increased amenability of blood cells and endothelial cells to apoptosis or activation (15), which trigger the production of MPs (16). The expression of the negatively charged phosphatidylserine (PS) on the surface of MPs facilitates the assembly of coagulation factors that contain positively charged domains, such as factors II, VII, IX, and X (17). MPs have been suggested to be used in predicting thrombosis in patients with malignancies (18). In MPN, a similar suggestion has been made after reporting higher values of MPs in patients with thrombosis $(6,7,14)$. Our MPN patients had significantly higher pathological values of MP-activity and higher levels of both PMPs and RMPs compared to healthy individuals. This is consistent with other studies reporting higher MP-activity (5-7) and higher MPs count $(4,8)$.

Previously, Charpentier et al. reported that according to the IPSET-thrombosis score, high-risk thrombocythemia patients had higher MPs counts than intermediate- or low-risk patients (19). In our study, the values of MPs were evaluated based 
on the presence of different thrombotic risk factors in MPN patients. The definite risk factors, including age $>60$ years and previous history of thrombosis, in conjunction with cardiovascular risk factors, including tobacco smoking, hypertension, and diabetes mellitus, have been associated with a higher risk of thrombosis in MPN patients $(20,21)$. Regarding the sex variable, some studies demonstrated that males are at a higher risk of developing thrombosis $(20,21)$, while others reported females to be at higher risk $(22,23)$. Our results showed that tobacco smoking and male sex are associated with higher pathological MP-activity. The clinical implication of these results is supported by the fact that these conditions are risk factors for thrombosis. Therefore, MPs may promote thrombogenesis more often and intensely in vulnerable patients; hence, they may be at a higher risk of thrombotic complications.

JAK $2^{\mathrm{V} 617 \mathrm{~F}}$ is not only a driver mutation contributing to the clinical and biological characterization of MPN; its presence or its higher allele burden has also been found to carry an increased risk of thrombosis in MPN $(24,25)$. This mutation may contribute to thrombosis by affecting the cellular and plasma components of hemostasis (26). The effect starts from the progenitor cells in the bone marrow, where the megakaryocyte in a JAK2 $2^{\mathrm{V} 617 \mathrm{~F}}$ knock-in mouse model of ET showed an increased ability of migratory activity and proplatelet formation, suggesting a change in the biological character of mutated cells (27). The produced platelets in mutated patients were also shown to circulate in an activated status, enhancing thrombin generation and amplifying further platelet activation leading to a vicious circle $(28,29)$. The status of activation has also been described for leukocytes and endothelial cells, and elevated plasma markers of thrombosis, including TF, d-dimer, MPs, and the status of acquired protein $\mathrm{C}$ resistance have been reported in association with JAK2 ${ }^{\mathrm{V} 617 \mathrm{~F}}$ mutation (29-31). We observed that plasma levels of PMPs, but not RMPs, were significantly higher in $\mathrm{JAK} 2^{\mathrm{V} 617 \mathrm{~F}}$-mutated patients. In a study by Zhang et al., JAK2 ${ }^{\mathrm{V} 617 \mathrm{~F}}$ mutation was associated with an increased level of PMPs, but no significant difference was observed for RMPs, endothelial MPs, or TFpositive MPs (8). These results can explain the contribution of JAK $2^{\mathrm{V} 617 \mathrm{~F}}$ mutation to the hypercoagulable state in MPN by supporting its mechanism of inducing persistent platelet activation leading to a proportional increase of PMPs (29). We found that average MP-activity levels were higher in $\mathrm{JAK} 2^{\mathrm{V} 617 \mathrm{~F}}$-mutated patients, though the difference was not statistically significant. Repeated measurements of MPs were performed for all MPN patients, including JAK2 $2^{\mathrm{V} 617 \mathrm{~F}}$ positive; thus, the examination was made in various stages of the disease and intensity of treatment. Due to the high risk of thrombosis in the presence of $\mathrm{JAK} 2^{\mathrm{V} 617 \mathrm{~F}}$ mutation, treatment can be intensified in order to prevent thrombosis. According to the individual risk assessment for each patient, treatment may include cytoreductive and antithrombotic therapy. It can be assumed that anticoagulant and antiplatelet therapy may have a greater effect on the procoagulant activity of MPs than on their count. Based on the literature, an effect of antiplatelet therapy on MP-activity can be assumed (32); however, its effect on the number of MPs remains inconsistent $(33,34)$. This study was conducted on a real cohort of MPN patients, so the isolated effect of each type of treatment on MP activity cannot be assessed.

Blood cell counts are debatable risk factors of thrombosis in MPN, with many diversities in the literature regarding their thrombosis-predicting thresholds. Therefore, we analyzed the values of MPs in context with the therapeutic targets recommended to achieve a complete hematologic response in ET and PV patients: platelets $\left(\leq 400 \times 10^{9} / 1\right)$; hematocrit $(<45 \%)$; and leukocytes $\left(<10 \times 10^{9} / 1\right)(35)$. In several studies, increased thrombotic occurrence in MPN patients was observed when exceeding these limits for platelets (36), hematocrit (37), and leukocytes (38). Our patients with higher values during the follow-up presented with significantly higher pathological MP-activity and/or higher MPs count than patients having blood counts within these limits. Thrombotic risk in PV is correlated to hematocrit level due to erythrocytes' effect on blood viscosity (39) and because erythrocytes can induce platelet activation leading to the increased procoagulant activity necessary for thrombosis, which has been recently demonstrated in a mouse model (40). Consistent with this notion, we found that PMPs and MPactivity levels were dependent on hematocrit value, in addition to the dependence of PMPs levels on platelet count. These results emphasize the role of blood elements and their crosstalk in the prothrombotic tendency in MPN patients.

The potential contribution of MPs to the hypercoagulable state in MPN has been demonstrated in several studies where high MP-activity levels were linked to the state of "thrombomodulin-resistance" observed in MPN patients (5). Moreover, high MPs count in ET has been associated with increased thrombin generation, increased peak height, and shortened lag time (4). We evaluated the direct relationship between MPs values and thrombotic complications in our cohort. Regardless of type or time of occurrence, patients who had thrombosis had significantly higher pathological MP-activity than thrombosis-free patients. Analyses of MPs results in patients who had thrombotic complications during the follow-up revealed that the levels of MPs did not differ significantly from patients without such events, which can be due to the received treatment.

In literature, cytoreductive therapy has been shown to significantly decrease the level of MPs $(14,19)$ and MPactivity $(5,6)$. Our results showed a significant decrease in the levels of MPs in blood samples obtained when cytoreductive treatment was used. This impact of cytoreduction on the levels of MPs may explain why there 
was no significant difference in their levels between patients with or without thrombosis during the follow-up. Reduction of MP levels and their procoagulant activity seems to be an effect of cytoreduction treatment through which the risk of thrombotic complications may be reduced. However, results regarding MPs and thrombosis during the follow-up should be treated with caution because of the small number of patients with thrombosis in this period (29 patients). Considering that ANA and HU were the most used agents in our cohort, we compared the effect of these two agents on MPs results. The levels of PMPs and MP-activity were significantly lower in the ANA arm than in the HU arm. Despite the major limitation here of having a low number of patients treated with either drug, our results seem to be consistent with the findings of Taniguchi et al., where ANA tended to reduce the levels of MPs more effectively than HU (14). However, the present study was not designed to compare the efficacy of these agents due to the small number of patients treated with these agents as monotherapy. As shown in Table IV, patients in the HU arm were significantly older than those in the ANA arm. In addition, HU patients presented more frequently with $\mathrm{JAK} 2^{\mathrm{V} 617 \mathrm{~F}}$ mutation, cardiovascular risk factors, and a history of thrombosis; thus, they were considered high-risk patients and received $\mathrm{HU}$ as recommended (41). These risk factors are associated with increased levels of MPs in our study. The different mechanisms of action of both drugs are another factor influencing the levels of MPs. Inhibiting megakaryocyte differentiation and platelet activity by ANA can decrease platelet level, and so the levels of platelet-derived MPs in the plasma (42). On the other hand, HU is a non-alkylating antimetabolite agent that blocks DNA synthesis, leading directly to cell apoptosis or secondarily can cause macrocytosis with expanded cell surface; in both cases, the cell becomes more prone to produce MPs (43). Due to the low number of patients treated with these drugs as monotherapy, the effect of these drugs in reducing the risk of thrombosis cannot be assessed only based on our results.

A limitation of this study is that in most patients, the examination of MPs was not performed at the time of MPN diagnosis, that is, before initiating the cytoreductive treatment. Examination of MPs under such conditions may accurately reveal the effect of treatment on the levels of MPs. Moreover, examination of MPs was performed within regular time intervals, i.e., at different disease stages and treatment intensity degrees, which may have affected the results of MPs in some patients. Another limitation is the small number of patients who had thrombotic complications during the follow-up, although from a clinical point of view, this is a success in MPN management. However, further prospective studies are needed to investigate MPs in a larger MPN cohort with different settings in which MPs can be evaluated before and after therapy initiation.

\section{Conclusion}

In the present study, BCR/ABL1-negative MPN patients had higher values of MPs than the healthy population. MPs values were elevated in the presence of thrombotic risk factors, including age $>60$ years, history of thrombosis, JAK2 ${ }^{\mathrm{V} 617 \mathrm{~F}}$ mutation, tobacco use, and male sex. Our results showed that preserving hematocrit, platelets, and leukocytes within the recommended therapeutic limits is crucial. Exceeding these limits may cause elevation of MPs, which possibly increases the risk of thrombosis. It can be concluded that the prothrombotic state of MPN patients is complex and multifactorial and that MPs may play a role in inducing thrombosis. During the follow-up, patients with thrombotic complications presented with no difference in MPs levels compared to patients without such events. Cytoreductive therapy may be responsible for these results.

Further prospective studies are needed to clarify the relationship between MPs and thrombotic occurrence in relation to the diagnosis, disease stage, and treatment level of intensity. Such studies can clarify the value of MPs in predicting thrombosis in these patients.

\section{Conflicts of Interest}

The Authors have no conflicts of interest to declare in relation to this study.

\section{Authors' Contributions}

M.H.A, J.K and M.P designed the study. M.H.A and L.R performed MPs analyses. M.H.A collected the data. P.O analyzed the data. M.H.A and J.K wrote the manuscript. M.P supervised the study. All Authors provided critical feedback and helped shape the manuscript.

\section{Acknowledgements}

This work was supported by a project (FNBr 65269705) for the research organization's conceptual development, supported by the Ministry of Health, Czech Republic.

\section{References}

1 Barteneva NS, Fasler-Kan E, Bernimoulin M, Stern JN, Ponomarev ED, Duckett L and Vorobjev IA: Circulating microparticles: square the circle. BMC Cell Biol 14: 23, 2013. PMID: 23607880. DOI: 10.1186/1471-2121-14-23

2 Nomura S and Shimizu M: Clinical significance of procoagulant microparticles. J Intensive Care 3(1): 2, 2015. PMID: 25705427. DOI: $10.1186 / \mathrm{s} 40560-014-0066-\mathrm{Z}$

3 Lacroix R, Dubois C, Leroyer AS, Sabatier F and Dignat-George F: Revisited role of microparticles in arterial and venous thrombosis. J Thromb Haemost 11 Suppl 1: 24-35, 2013. PMID: 23809108. DOI: $10.1111 /$ jth.12268

4 Trappenburg MC, van Schilfgaarde M, Marchetti M, Spronk HM, ten Cate H, Leyte A, Terpstra WE and Falanga A: Elevated 
procoagulant microparticles expressing endothelial and platele markers in essential thrombocythemia. Haematologica 94(7): 911-918, 2009. PMID: 19508974. DOI: 10.3324/haematol.13774

5 Duchemin J, Ugo V, Ianotto JC, Lecucq L, Mercier B and Abgrall JF: Increased circulating procoagulant activity and thrombin generation in patients with myeloproliferative neoplasms. Thromb Res 126(3): 238-242, 2010. PMID: 20656333. DOI: $10.1016 /$ j.thromres.2010.06.025

6 Kissova J, Ovesna P, Bulikova A, Zavřelova J and Penka M: Increasing procoagulant activity of circulating microparticles in patients with Philadelphia-negative myeloproliferative neoplasms: a single-centre experience. Blood Coagul Fibrinolysis 26(4): 448-453, 2015. PMID: 25828967. DOI: 10.1097/MBC.0000000000000293

7 Marchetti M, Tartari CJ, Russo L, Panova-Noeva M, Leuzzi A, Rambaldi A, Finazzi G, Woodhams B and Falanga A: Phospholipid-dependent procoagulant activity is highly expressed by circulating microparticles in patients with essential thrombocythemia. Am J Hematol 89(1): 68-73, 2014. PMID: 24009132. DOI: 10.1002/ajh.23590

8 Zhang W, Qi J, Zhao S, Shen W, Dai L, Han W, Huang M, Wang Z, Ruan C, Wu D and Han Y: Clinical significance of circulating microparticles in $\mathrm{Ph}^{-}$myeloproliferative neoplasms. Oncol Lett 14(2): 2531-2536, 2017. PMID: 28789461. DOI: 10.3892/ol. 2017.6459

9 Arber DA, Orazi A, Hasserjian R, Thiele J, Borowitz MJ, Le Beau MM, Bloomfield CD, Cazzola M and Vardiman JW: The 2016 revision to the World Health Organization classification of myeloid neoplasms and acute leukemia. Blood 127(20): 23912405, 2016. PMID: 27069254. DOI: 10.1182/blood-2016-03643544

10 Stein B, Patel K, Scherber R, Yu J, Paranagama D and Miller C: Mortality and causes of death of patients with polycythemia vera: Analysis of the reveal prospective, observational study. Blood 136(Supplement 1): 36-37, 2021. DOI: 10.1182/blood2020-137144

11 Lekovic D, Gotic M, Sefer D, Mitrovic-Ajtic O, Cokic V and Milic N: Predictors of survival and cause of death in patients with essential thrombocythemia. Eur J Haematol 95(5): 461-466, 2015. PMID: 25645731. DOI: 10.1111/ejh.12517

12 Barbui T, Carobbio A, Cervantes F, Vannucchi AM, Guglielmelli P, Antonioli E, Alvarez-Larrán A, Rambaldi A, Finazzi G and Barosi G: Thrombosis in primary myelofibrosis: incidence and risk factors. Blood 115(4): 778-782, 2010. PMID: 19965680. DOI: 10.1182/blood-2009-08-238956

13 Martin K: Risk factors for and management of MPN-associated bleeding and thrombosis. Curr Hematol Malig Rep 12(5): 389396, 2017. PMID: 28948496. DOI: 10.1007/s11899-017-0400-3

14 Taniguchi Y, Tanaka H, Luis EJ, Sakai K, Kumode T, Sano K, Serizawa K, Rai S, Morita Y, Hanamoto H, Tsubaki K, Nishio $\mathrm{K}$ and Matsumura I: Elevated plasma levels of procoagulant microparticles are a novel risk factor for thrombosis in patients with myeloproliferative neoplasms. Int J Hematol 106(5): 691703, 2017. PMID: 28780601. DOI: 10.1007/s12185-017-2302-5

15 Falanga A and Marchetti M: Thrombosis in myeloproliferative neoplasms. Semin Thromb Hemost 40(3): 348-358, 2014. PMID: 24610470. DOI: $10.1055 / \mathrm{s}-0034-1370794$

16 Mooberry MJ and Key NS: Microparticle analysis in disorders of hemostasis and thrombosis. Cytometry A 89(2): 111-122, 2016. PMID: 25704723. DOI: 10.1002/cyto.a.22647
17 Voukalis C, Shantsila E and Lip GYH: Microparticles and cardiovascular diseases. Ann Med 51(3-4): 193-223, 2019. PMID: 31007084. DOI: 10.1080/07853890.2019.1609076

18 García-Santos G, Serrano Pertierra E, Fernández Hevia M, Duque Alcorta JM, Sánchez Domínguez L, Blanco López MC and García Flórez LJ: Potential of extracellular microvesicles as new colorectal cancer biomarker. Br J Surg 108: znab160.075, 2021. DOI: $10.1093 /$ bjs/znab160.075

19 Charpentier A, Lebreton A, Rauch A, Bauters A, Trillot N, Nibourel O, Tintillier V, Wemeau M, Demory JL, Preudhomme C, Jude B, Lecompte T, Cambier N and Susen S: Microparticle phenotypes are associated with driver mutations and distinct thrombotic risks in essential thrombocythemia. Haematologica 101(9): e365-e368, 2016. PMID: 27247323. DOI: 10.3324/ haematol.2016.144279

20 Landolfi R, Di Gennaro L, Barbui T, De Stefano V, Finazzi G, Marfisi R, Tognoni G, Marchioli R and European Collaboration on Low-Dose Aspirin in Polycythemia Vera (ECLAP): Leukocytosis as a major thrombotic risk factor in patients with polycythemia vera. Blood 109(6): 2446-2452, 2007. PMID: 17105814. DOI: $10.1182 /$ blood-2006-08-042515

21 Carobbio A, Thiele J, Passamonti F, Rumi E, Ruggeri M, Rodeghiero F, Randi ML, Bertozzi I, Vannucchi AM, Antonioli E, Gisslinger H, Buxhofer-Ausch V, Finazzi G, Gangat N, Tefferi A and Barbui T: Risk factors for arterial and venous thrombosis in WHO-defined essential thrombocythemia: an international study of 891 patients. Blood 117(22): 5857-5859, 2011. PMID: 21490340. DOI: 10.1182/blood-2011-02-339002

22 Stein BL, Saraf S, Sobol U, Halpern A, Shammo J, Rondelli D, Michaelis L, Odenike O, Rademaker A, Zakarija A, McMahon B, Spivak JL and Moliterno AR: Age-related differences in disease characteristics and clinical outcomes in polycythemia vera. Leuk Lymphoma 54(9): 1989-1995, 2013. PMID: 23245211. DOI: 10.3109/10428194.2012.759656

23 Cerquozzi S, Barraco D, Lasho T, Finke C, Hanson CA, Ketterling RP, Pardanani A, Gangat N and Tefferi A: Risk factors for arterial versus venous thrombosis in polycythemia vera: a single center experience in 587 patients. Blood Cancer J 7(12): 662, 2017. PMID: 29282357. DOI: 10.1038/s41408-017-0035-6

24 Seguro FS, Teixeira LLC, da Rosa LI, da Silva WF, Nardinelli L, Bendit I and Rocha V: Risk factors and incidence of thrombosis in a Brazilian cohort of patients with Philadelphianegative myeloproliferative neoplasms. J Thromb Thrombolysis 49(4): 667-672, 2020. PMID: 31898273. DOI: 10.1007/s11239019-02029-y

25 Dahabreh IJ, Zoi K, Giannouli S, Zoi C, Loukopoulos D and Voulgarelis M: Is JAK2 V617F mutation more than a diagnostic index? A meta-analysis of clinical outcomes in essential thrombocythemia. Leuk Res 33(1): 67-73, 2009. PMID: 18632151. DOI: 10.1016/j.leukres.2008.06.006

26 Barbui T and Falanga A: Molecular biomarkers of thrombosis in myeloproliferative neoplasms. Thromb Res 140 Suppl 1: S71S75, 2016. PMID: 27067982. DOI: 10.1016/S00493848(16)30102-5

27 Hobbs CM, Manning H, Bennett C, Vasquez L, Severin S, Brain L, Mazharian A, Guerrero JA, Li J, Soranzo N, Green AR, Watson SP and Ghevaert C: JAK2V617F leads to intrinsic changes in platelet formation and reactivity in a knock-in mouse model of essential thrombocythemia. Blood 122(23): 3787-3797, 2013. PMID: 24085768. DOI: 10.1182/blood-2013-06-501452 
28 Panova-Noeva M, Marchetti M, Spronk HM, Russo L, Diani E, Finazzi G, Salmoiraghi S, Rambaldi A, Barbui T, Ten Cate H and Falanga A: Platelet-induced thrombin generation by the calibrated automated thrombogram assay is increased in patients with essential thrombocythemia and polycythemia vera. Am J Hematol 86(4): 337-342, 2011. PMID: 21442635. DOI: 10.1002/ajh. 21974

29 Matsuura S, Thompson CR, Belghasem ME, Bekendam RH, Piasecki A, Leiva O, Ray A, Italiano J, Yang M, Merill-Skoloff G, Chitalia VC, Flaumenhaft R and Ravid K: Platelet dysfunction and thrombosis in JAK2 $2617 \mathrm{~F}$-mutated primary myelofibrotic mice. Arterioscler Thromb Vasc Biol 40(10): e262e272, 2020. PMID: 32814440. DOI: 10.1161/ATVBAHA. 120.314760

30 Alvarez-Larrán A, Arellano-Rodrigo E, Reverter JC, Domingo A, Villamor N, Colomer D and Cervantes F: Increased platelet, leukocyte, and coagulation activation in primary myelofibrosis. Ann Hematol 87(4): 269-276, 2008. PMID: 17899078. DOI: 10.1007/s00277-007-0386-3

31 Marchetti M, Castoldi E, Spronk HM, van Oerle R, Balducci D, Barbui T, Rosing J, Ten Cate $\mathrm{H}$ and Falanga A: Thrombin generation and activated protein $\mathrm{C}$ resistance in patients with essential thrombocythemia and polycythemia vera. Blood 112(10): 4061-4068, 2008. PMID: 18768782. DOI: 10.1182/ blood-2008-06-164087

32 Kim HJ, Choi EH, Lim YJ and Kil HR: The usefulness of platelet-derived microparticle as biomarker of antiplatelet therapy in Kawasaki disease. J Korean Med Sci 32(7): 11471153, 2017. PMID: 28581272. DOI: $10.3346 / \mathrm{jkms} .2017$. 32.7.1147

33 Skeppholm M, Mobarrez F, Malmqvist $\mathrm{K}$ and Wallén H: Platelet-derived microparticles during and after acute coronary syndrome. Thromb Haemost 107(6): 1122-1129, 2012. PMID: 22371053. DOI: 10.1160/TH11-11-0779

34 Duarte RC, Gonçalves LH, Campos FM, Filho OA, Alves MT, Fernandes AP, Borges KB, Dusse LM, Faria MC, Gonçalves GS, Bosco AA, Sandrim VC and Carvalho MG: Effect of acetylsalicylic acid on platelet activation and oxidative profile in a set of Brazilian patients with type 2 diabetes mellitus. Blood Coagul Fibrinolysis 26(2): 123-130, 2015. PMID: 25325344. DOI: $10.1097 / \mathrm{MBC} .0000000000000199$

35 Barosi G, Mesa R, Finazzi G, Harrison C, Kiladjian JJ, Lengfelder E, McMullin MF, Passamonti F, Vannucchi AM, Besses C, Gisslinger H, Samuelsson J, Verstovsek S, Hoffman R, Pardanani A, Cervantes F, Tefferi A and Barbui T: Revised response criteria for polycythemia vera and essential thrombocythemia: an ELN and IWG-MRT consensus project. Blood 121(23): 4778-4781, 2013. PMID: 23591792. DOI: 10.1182/blood-2013-01-478891

36 Alvarez-Larrán A, Pereira A, Cervantes F, Arellano-Rodrigo E, Hernández-Boluda JC, Ferrer-Marín F, Angona A, Gómez M, Muiña B, Guillén H, Teruel A, Bellosillo B, Burgaleta C, Vicente $\mathrm{V}$ and Besses $\mathrm{C}$ : Assessment and prognostic value of the European LeukemiaNet criteria for clinicohematologic response, resistance, and intolerance to hydroxyurea in polycythemia vera. Blood 119(6): 1363-1369, 2012. PMID: 22160617. DOI: 10.1182/blood-2011-10-387787
37 Marchioli R, Finazzi G, Specchia G, Cacciola R, Cavazzina R, Cilloni D, De Stefano V, Elli E, Iurlo A, Latagliata R, Lunghi F, Lunghi M, Marfisi RM, Musto P, Masciulli A, Musolino C, Cascavilla N, Quarta G, Randi ML, Rapezzi D, Ruggeri M, Rumi E, Scortechini AR, Santini S, Scarano M, Siragusa S, Spadea A, Tieghi A, Angelucci E, Visani G, Vannucchi AM, Barbui T and CYTO-PV Collaborative Group: Cardiovascular events and intensity of treatment in polycythemia vera. N Engl J Med 368(1): 22-33, 2013. PMID: 23216616. DOI: 10.1056/ NEJMoa1208500

38 Enblom-Larsson A, Girodon F, Bak M, Hersby D, Jooste V, Hasselbalch H, Johansson P and Andreasson B: A retrospective analysis of the impact of treatments and blood counts on survival and the risk of vascular events during the course of polycythaemia vera. Br J Haematol 177(5): 800-805, 2017. PMID: 28474342. DOI: $10.1111 / \mathrm{bjh} .14625$

39 Gordeuk VR, Key NS and Prchal JT: Re-evaluation of hematocrit as a determinant of thrombotic risk in erythrocytosis. Haematologica 104(4): 653-658, 2019. PMID: 30872370. DOI: 10.3324/haematol.2018.210732

40 Klatt C, Krüger I, Zey S, Krott KJ, Spelleken M, Gowert NS, Oberhuber A, Pfaff L, Lückstädt W, Jurk K, Schaller M, AlHasani H, Schrader J, Massberg S, Stark K, Schelzig H, Kelm $\mathrm{M}$ and Elvers $\mathrm{M}$ : Platelet-RBC interaction mediated by FasL/FasR induces procoagulant activity important for thrombosis. J Clin Invest 128(9): 3906-3925, 2018. PMID: 29952767. DOI: $10.1172 /$ JCI92077

41 Falanga A, Marchetti M and Schieppati F: Prevention and management of thrombosis in BCR/ABL-negative myeloproliferative neoplasms. Hamostaseologie 41(1): 48-57, 2021. PMID: 33588455. DOI: 10.1055/a-1334-3259

42 Takaishi K, Takeuchi M, Tsukamoto S, Takayama N, Oshima M, Kimura K, Isshiki Y, Kayamori K, Hino Y, Oshima-Hasegawa N, Mitsukawa S, Takeda Y, Mimura N, Ohwada C, Iseki T, Nakamura S, Eto K, Iwama A, Yokote K, Nakaseko C and Sakaida E: Suppressive effects of anagrelide on cell cycle progression and the maturation of megakaryocyte progenitor cell lines in human induced pluripotent stem cells. Haematologica 105(5): e216-e220, 2020. PMID: 31488559. DOI: 10.3324/ haematol.2018.214841

43 Antonioli E, Guglielmelli P, Pieri L, Finazzi M, Rumi E, Martinelli V, Vianelli N, Luigia Randi M, Bertozzi I, De Stefano V, Za T, Rossi E, Ruggeri M, Elli E, Cacciola R, Cacciola E, Pogliani E, Rodeghiero F, Baccarani M, Passamonti F, Finazzi G, Rambaldi A, Bosi A, Cazzola M, Barbui T, Vannucchi AM and AGIMM Investigators: Hydroxyurea-related toxicity in 3,411 patients with Ph'-negative MPN. Am J Hematol 87(5): 552-554, 2012. PMID: 22473827. DOI: 10.1002/ajh.23160
Received June 14, 2021

Revised July 28, 2021

Accepted July 29, 2021 